\title{
Tropicalismo e (in)disciplina: Gregori Warchavchik e Wladimiro Acosta
}

Tropicalism and (in)discipline: Gregori Warchavchik and Wladimiro Acosta

\section{RICARDO DE SOUZA ROCHA'}

Universidade Federal de Santa Maria / Cachoeira do Sul, RS, Brasil

\begin{abstract}
1. Docente adjunto do curso de Arquitetura e do Programa de Pós-Graduação em Arquitetura, Urbanismo e Paisagismo da Universidade Federal de Santa Maria (UFSM) - Campus Cachoeira do Sul. E-mail: $<$ ricardo.rocha@ufsm.br>.
\end{abstract}

RESUMO: Este artigo trata das relações (arquitetônicas) entre Gregori Warchavchik e Wladimiro Acosta, através de uma atenção especial conferida a aspectos menores de suas obras iniciais. A partir desta aproximação à produção dos dois arquitetos, são feitas sugestões adicionais sobre a circulação de ideias arquitetônicas entre estratos geográficos e culturais, além de serem fornecidas pistas sobre as relações (arquitetônicas) entre Brasil e Argentina.

PALAVRAS-CHAVE: Gregori Warchavchik. Wladimiro Acosta. Arquitetura moderna. América Latina.

ABSTRACT: This study focuses on the (architectural) relations between Gregori Warchavchik and Wladimiro Acosta, giving close attention to minor aspects of their early works. Exploring this approach, some additional suggestions are made about the circulation of ideas between cultural layers and about the (architectural) relations between Brazil and Argentina.

KEYWORDS: Gregori Warchavchik. Wladimiro Acosta. Modern architecture. Latin America. 
Este artigo propõe uma mirada quase "microscópica", voltada aos detalhes, que valoriza os pormenores - spie na definição do historiador Carlo Ginzburg -, sobre a obra de Gregori Warchavchik e Wladimiro Acosta. Entre a grande tela do historiador da cultura e a atenção às nuances de cada pincelada do crítico de arte, o historiador da arquitetura deve fazer uso de todos os recursos disponíveis: "a oposição entre uma abordagem sócio-histórica da arte e a abordagem de um connaisseur [é] não só absurda como tremendamente prejudicial", alerta Ginzburg. ${ }^{2}$ Tanto ou mais que o exemplo do historiador italiano, é interessante assinalar o método utilizado por David Arrigucci Jr. em O cacto e as ruínas. ${ }^{3}$ Como aponta Fábio de Souza Andrade na apresentação do livro, "a escavação microscópica, o panorama abrangente são recursos que o autor alterna [...], ora enfocando o detalhe bem apanhado, ora abrindo-se para contextos mais amplos". ${ }^{4}$ A referência é duplamente pertinente, na medida em que Arrigucci propõe uma análise do poema "O cacto" de Manuel Bandeira, onde o "banal representante da flora brasileira" toma pé e "se amplia em círculos, no tempo e no espaço", articulando-se com a produção de outros modernos, como o pintor Lasar Segall, cunhado de Warchavchik, e de "As ruínas de Selinunte", de Murilo Mendes, sobre as emanações das ruínas de um tempo clássico em meio à paisagem siciliana, onde colunas dóricas, "severas se erguendo", procuram-se, organizam-se, "verticalmente, horizontalmente".

Fontes iniciais comuns (como a arquitetura de Ivan Fomin), técnicas de representação, um indício aqui outro ali, vão compondo uma espécie de mosaico le não necessariamente montando todas as peças de um quebracabeça completo), cujas ressonâncias afiançam relações apenas suspeitadas, esboçando outras insuspeitadas. Norte e Sul, Luz e Sombra, Baven und Natur constituem os elementos de uma trama, ao mesmo tempo urdidura conceitual e drama vivido, daqueles que buscaram um lugar ao sol e ao sul do Equador. Dividindo-se em dois momentos, o primeiro (e principal) discutido nas três seções iniciais, o artigo trata das relações entre os dois arquitetos, o "brasileiro" e o "argentino", a partir de sua origem e trajetória comuns. Em um segundo momento, comenta-se brevemente a circulação de ideias arquitetônicas entre estratos geográficos e culturais. Desse modo, emergem ainda, para além do tema da condição/contribuição dos imigrantes para a cultura arquitetônica latino-americana, iá discutida por outros autores, vestígios das trocas culturais e arquitetônicas entre Brasil e Argentina, todavia, em grande medida, por mapear. 
Grigori I. Warchávtchik (Gregori Warchavchik, 1896-1972) e Wladímir Konstantinóvski (Wladimiro Acosta, 1900-1967) nasceram em Odessa, na Ucrânia, nos anos finais do século XIX. Tanto um quanto o outro possuíam ascendência judia - a família de Acosta era sefardita ${ }^{5}$ - e frequentaram a escola de artes da cidade. Wladímir entre 1911 e 1917, Grigori a partir de 1912. Com a Revolução Bolchevique, Warchávtchik parte para Roma em 1918, Konstantinóvski lá já se encontra em 1919. Um ano depois ambos estão diplomados como "professores de desenho arquitetônico" pelo Instituto Superior de Belas-Artes de Roma e colaboram como arquitetos no escritório de Marcello Piacentini (1881-1960). Posteriormente, desenvolvem sua atividade profissional na América do Sul-depois de uma breve passagem por São Paulo, ${ }^{\circ}$ Acosta fixa-se definitivamente em Buenos Aires. A incrível semelhança de suas trajetórias iniciais e do papel que desempenharam no desenvolvimento da arquitetura moderna no Brasil e na Argentina já foi observada mais de uma vez.

Não obstante, nem Anat Falbel, 7 em seus artigos sobre os dois arquitetos, nem José Lira, ${ }^{8}$ em seu amplo trabalho sobre Warchavchik, parecem concordar com a opinião dos historiadores argentinos, ${ }^{9}$ exemplificada pela observação de Jorge Francisco Liernur, em artigo sobre Acosta, para quem os dois arquitetos tinham "una larga amistad". ${ }^{10}$

Nesse sentido, procurando dar um passo adiante em relação a tal impasse, embora sem a pretensão de proferir a palavra final no assunto, serão mostrados, a seguir, indícios claros das relações (arquitetônicas) entre ambos, através do exame atento de sua produção, desde os anos de estudo dos dois ucranianos em Roma até a breve passagem de Acosta por São Paulo, entre 1930 e 1931.

\section{ESTILO GRÁFICO VERSUS SÍNTESE COMPOSITIVA}

Através das imagens conhecidas de alguns dos primeiros projetos dos dois arquitetos, realizados em Roma no início dos anos 1920 e publicados inicialmente pelo próprio Acosta em Vivienda y ciudad' ${ }^{1}$ e por Geraldo Ferraz em sua monografia sobre Warchavchik, ${ }^{12}$ identificam-se semelhanças significativas que permitem supor uma eventual troca de informações entre os então jovens arquitetos.

$\bigcirc$ tipo de representação gráfica é muito parecido, mas seria necessário verificar os originais, para saber, por exemplo, se são todos desenhos em grayscale
6. Acosta chegou a participar do IV Congresso Pan-Americano de Arquitetos, em 1930, no Rio de Janeiro.

7. Falbel (2009).

8. Lira (2011).

9. A expressão é de Lira (2011, p. 87): "os historiadores argentinos insistem na proximidade entre Wladimiro Acosta e Gregori Warchavchik".

10. Liernur (2007, p. 265). Ons e Campos (2007) vão mais longe e identificam aproximações, nas obras dos dois arquitetos, em relação ao tratamento do binômio "corpo-pele" - isto é, volumes fechados e, afastados e acoplados a estes, planos delimitando "vazios".

11. Acosta (1936).

12. Ferraz (1965). 
13. Brumfield (1991).

14. Lira (2011, p. 84). ou coloridos. De qualquer forma, José Lira iá identificou claramente a fonte de Warchavchik: as propostas do arquiteto russo Ivan Fomin, adepto do style moderne de seu mestre Fedor Shekhtel, ${ }^{13}$ nos primeiros anos do século passado. $\bigcirc$ "Projeto de uma residência" de Warchavchik (Figura 1), de fato, é uma reelaboração muito próxima do "Projeto para a residência de artista" de Fomin (Figura 2), bem como a também assinalada reinterpretação do projeto para a residência do príncipe Volkonski, transformado por Warchavchik em teatro. Há algo de curioso nesta última operação, relativamente incomum do ponto de vista de certa abstração programática necessária para utilizar elementos de composição e ornamentação de uma residência em um projeto de teatro - talvez porque a casa de um príncipe, como a de uma diva, seja um tanto teatral. Por outro lado, como será comentado adiante, Acosta incorporará mecanismos da arquitetura teatral em seus projetos residenciais. Contudo, enquanto Warchavchik parece mais preocupado inicialmente com os aspectos simbólicos e representativos da arquitetura, Acosta entende-a como uma machine à habiter: a malfadada expressão de Le Corbusier indicando aqui a possibilidade do entendimento da arquitetura como um dispositivo regulável, de acordo com as necessidades do usuário, não um símbolo estático de sua condição social.

Nas palavras de Lira, "a composição geral e os diversos elementos decorativos são indiscutivelmente os mesmos" (na minha opinião são indiscutivelmente semelhantes, mas não exatamente os mesmos) e "também o estilo gráfico do copista confirma o original". ${ }^{14} \mathrm{E}$ este ponto merece maior atenção. Se repararmos no projeto de residência para a colônia italiana em Tien-Tsin de Acosta (Figura 3),

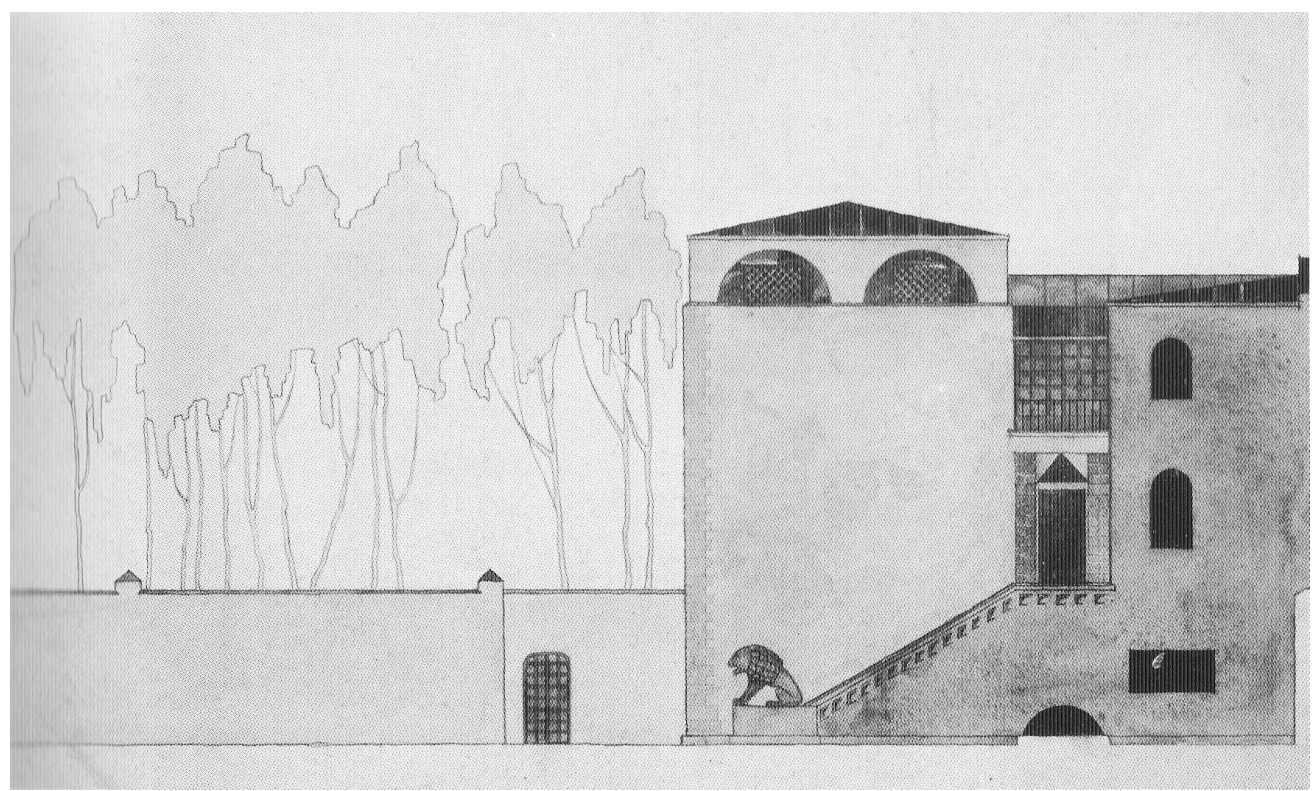

Figura 1 - Projeto de residência por Gregori Warchavchik, 1921. Fonte: Ferraz (1965, p. 49). 


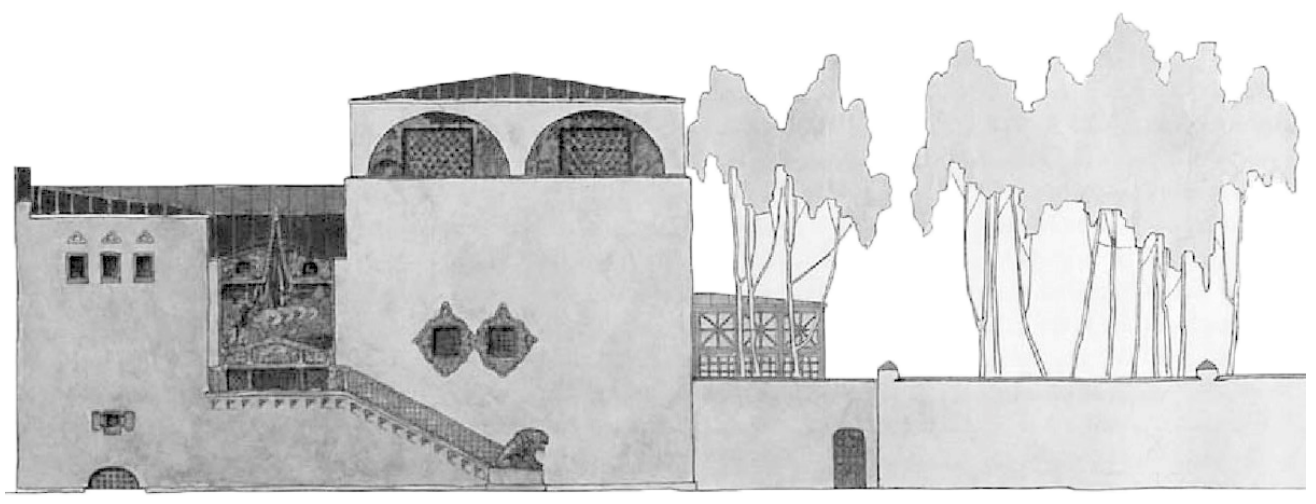

Figura 2 - Projeto de residência para um artista por Ivan Fomin, 1906. Fonte: Yezhegodnik Obshchestva Arkhitektorov-Khudozhnikov (Anuário da Sociedade de Arquitetos-Artistas). ${ }^{15}$

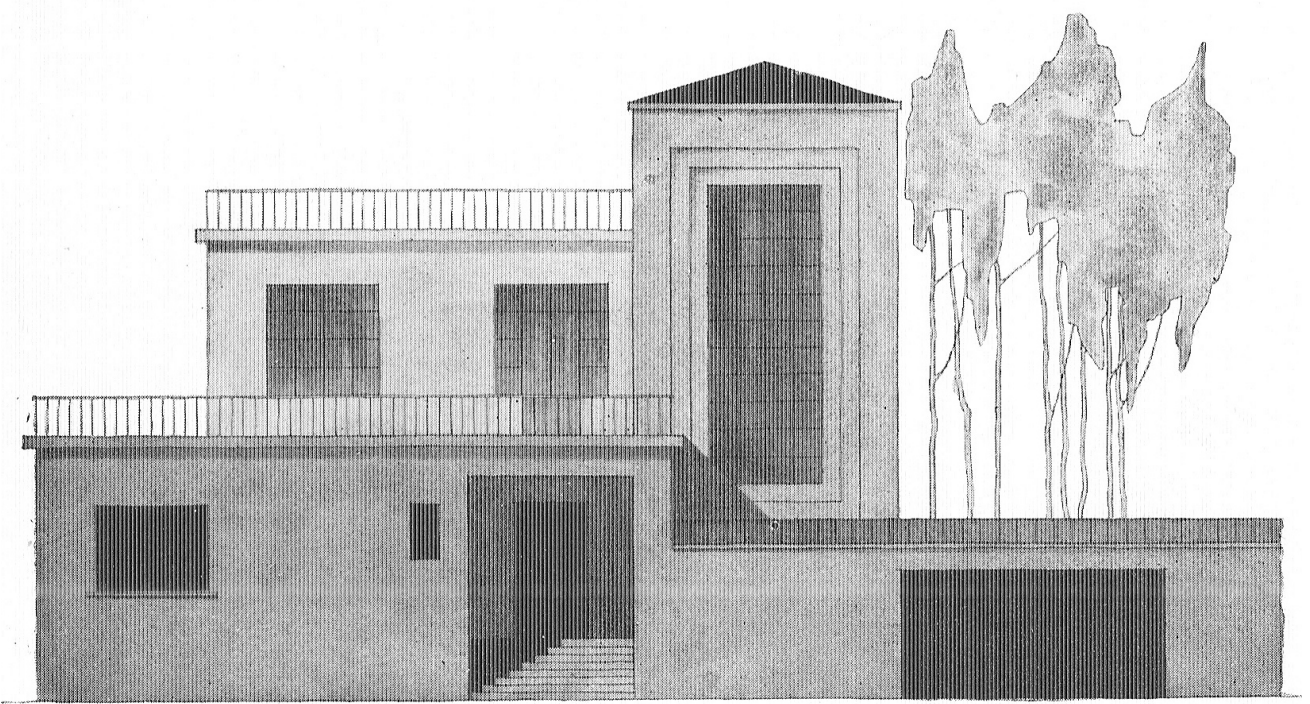

Figura 3 - Projeto de Residência em Tien-Tsin por Wladimiro Acosta, 1921. Fonte: Acosta (1936, p. 16).

a representação da vegetação é em tudo semelhante à de Fomin e, por extensão, à de Warchavchik - lembre-se: os dois colegas de turma se formaram no mesmo ano em Roma ${ }^{16}$ e as propostas que apresentam têm a mesma data. ${ }^{17}$ Além disso, se Warchavchik apresenta também um projeto de teatro e de um prédio de apartamentos, ambos, ele e Acosta, propõem habitações geminadas e uma residência de maior porte. Nesse sentido, há semelhanças de expressão gráfica, composição geral e programas nas propostas dos dois (três) arquitetos.

Liernur acredita, em razão de um documento datado do mesmo ano de 1921 , no qual Acosta toma conhecimento da Villa Schwob de Le Corbusier (figura 4), que esta, juntamente ao neoplasticismo holandês, seriam suas fontes. ${ }^{18}$ Entretanto, a articulação entre volumes verticais e horizontais ainda está a meio caminho das
15. Disponível em: <https:// bit.ly/2kd10kX>. Acesso em: 21 maio 2018.

16. Lira (2011, p. 70) reproduz documento onde aparecem os nomes de Warchavchik e Wladimiro em um "registro de aprovação" no $3^{\circ}$ ano do Curso Especial de Arquitetura, ambos com nota sete.

17. As viviendas apareadas de Acosta estão datadas, no entanto, de 1920.

18. Liernur (2007, p. 266-267). 
19. Na primeira edição a imagem aparece na página 62 e não na página 61 , como nas demais edições dos anos 1920 e 1930.

20. Apesar de nascido em uma comunidade judaica na Ucrânia, Warchavchik sempre se apresentou como russo (Lira, 2011, p. 37)

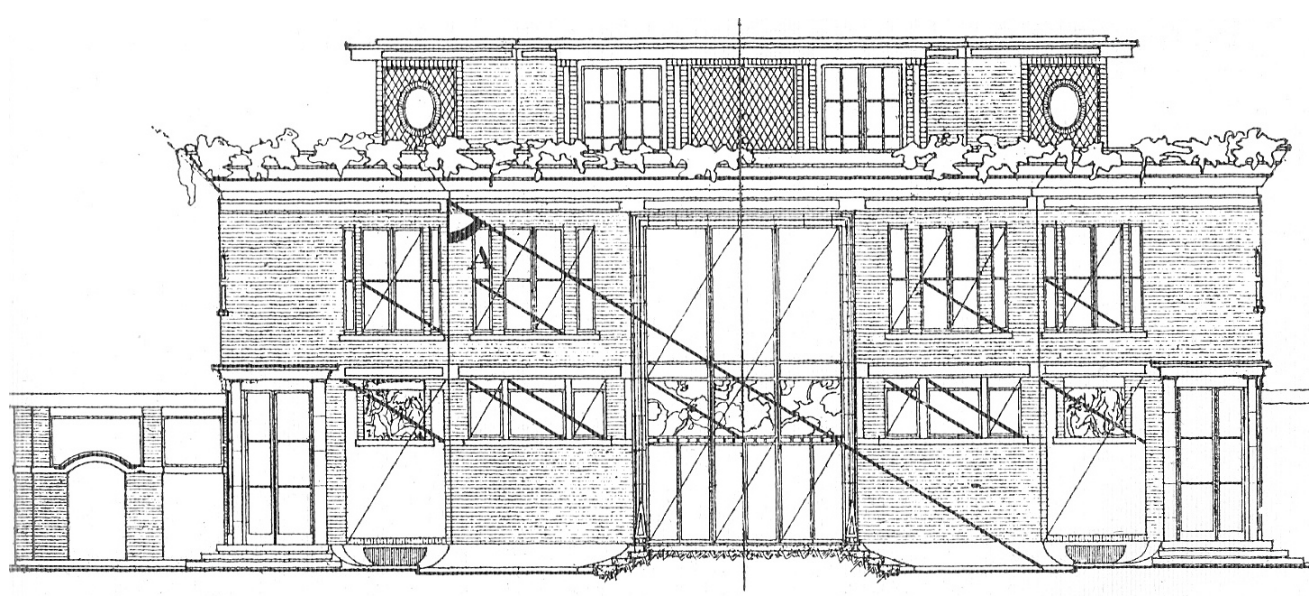

Figura 4 - Projeto para a Villa Schwob por Le Corbusier, 1916. Fonte: Le Corbusier (1923, p. 62). ${ }^{19}$

especulações neoplasticistas e as proposições de Fomin/Warchavchik. Da direita para a esquerda (no projeto de Acosta) temos a mesma sequência de Fomin espelhada em Warchavchik: (1) volume horizontal + vegetação; (2) volume vertical + escadaria (paralela longitudinalmente à edificação em Fomin/Warchavchik, no eixo transversal ortogonal em Acosta); (3) volumes intermédios (altura intermediária entre os volumes horizontais e verticais anteriores). Na verdade, a volumetria de Fomin é predominantemente horizontal, a de Warchavchik acentuadamente vertical e a de Acosta estabelece um maior equilíbrio e dinamismo entre os dois polos, talvez em razão de seu contato com o neoplasticismo. Já a fenestração e a discreta modenatura abstrato-geométrica parecem, de fato, mais próximas da Villa Schwob. Acosta mostra-se, assim, do ponto de vista do desenvolvimento posterior da linguagem dos dois arquitetos, em direção à corrente principal do movimento moderno, mais maduro, com um conjunto mais amplo de referências, e até mesmo os terraços característicos de suas casas dos anos 1930 já estão presentes.

O mais importante, entretanto, é a constatação de que havia pelo menos uma fonte comum para as propostas dos dois arquitetos naquele momento. Por outro lado, de modo um tanto diferente de Lira, que entende a opção de Warchavchik em buscar inspiração em Fomin como "reveladora", a razão por trás da busca de inspiração em propostas distantes no espaço, geograficamente falando, e no tempo - os projetos escolhidos de Fomin contavam com mais de uma década e, àquela altura, ele próprio já havia sido seduzido pela voga do revivalismo neoclássico -, continua em aberto. Acosta e Warchavchik voltavam-se para a Rússia por questões arquitetônicas? Ou culturais, no sentido de uma possível condição de estrangeiros em busca de suas raízes?20 Ou por ambos os motivos? 
Independentemente das razões, levando-se em conta o depoimento de Acosta em Vivienda y ciudad, as propostas dele e de Warchavchik naquele momento são indícios da assimilação de procedimentos treinados em sua formação:

22. Arrigucci Jr. (2000, p. 16)

¿En qué consistía la enseñanza de las academias en aquella época, y con qué caudal de conocimientos dotaba a sus egresados?

Copias de antiguos modelos constituían la base del aprendizaje. Se estudiaba sus proporciones, su plástica, pero se descuidaba por completo el análisis de las razones técnicas y la finalidad de su formación. La historia puramente anecdótica de la arquitectura y del arte en general quedaba totalmente desvinculada de la historia universal. ${ }^{21}$

Destaque-se, novamente, a maior autonomia e segurança aparente de Acosta em relação a Warchavchik. As propostas deste último são variações dos projetos de Fomin, em um procedimento ainda muito próximo do descrito por Acosta, e assinalado por Lira, onde o estilo gráfico do copista confirma o original. Já Acosta, ainda que utilizando o mesmo "estilo gráfico", reelabora um conjunto maior de referências - Fomin, Le Corbusier, De Stijl - alcançando, assim, uma proposição bem mais consistente, em seu equilíbrio dinâmico de horizontais e verticais, provavelmente pelo estudo do neoplasticismo - o que curiosa e contraditoriamente o aproxima mais de Fomin do que a reelaboração um tanto literal de Warchavchik.

Nesse sentido, sem querer forçar os termos, pode-se lembrar o comentário de David Arrigucci sobre o entendimento de T. S. Eliot quanto à capacidade mimética do poeta moderno, "não no sentido da representação [...] por meio de réplicas [...], mas no de formar, pelo movimento da imaginação, harmonias paralelas". ${ }^{22}$ A síntese elaborada por Acosta, se não alcança o despojamento absoluto e o dinamismo enfático da linguagem de vanguarda daqueles anos, tem o mérito de fundir referências diversas em um todo coerente.

\section{O CACTO E A SOMBRA}

cacto, "belo, áspero, intratável", do poema de Manuel Bandeira é contemporâneo dos cactos de Tarsila do Amaral e Lasar Segall. Segall, como se sabe, era casado com Jenny Klabin, irmã de Mina Klabin, esposa de Warchavchik. Mina, por sua vez, elaborava o paisagismo das casas de seu marido utilizando dracenas, guapuruvus e mandacarus (cactos). É tentador imaginar o cacto como um personagem, como o faz Bandeira. Observando as fotos das atividades da elite cultural e econômica em torno de Warchavchik, é possível encontrar o vegetal 
23. Como é possível verificar nas páginas da Architectural Forum do final dos anos 1920 .

24. Mário de Andrade apud Ferraz $(1965$, p. 26).

25. Revista de Arquitetura (1936). não só em pinturas, como se fossem retratos, mas também em reuniões e festas, no teatro e mesmo no encontro com Lúcio Costa e Frank Lloyd Wright, na casa construída por Warchavchik no Rio de Janeiro, no início dos anos 1930. Algo como uma figura alegórica, expressão máxima da síntese entre primitivo e moderno tão em voga entre as vanguardas do século passado.

Em Bandeira o cacto é o protagonista de uma fábula contemporânea, de uma pequena tragédia cotidiana, que mescla imigração e destino, ao mesmo tempo lugar de chegada e sina; em Tarsila do Amaral é o modelo para a (de) formação de seu abaporu, do antropófago primitivo-modernista, que digere la cultura dos) europeus; e em Segall é símbolo da miséria e do sofrimento. Na polissemia de seu cubismo multifacetado, o cacto é não só um primitivo-modernista enraizado na paisagem local, como ainda um símbolo transnacional, dada sua presença nas vanguardas mexicanas, de Diego Rivera a Juan O'Gorman - ou na arquitetura do sul dos Estados Unidos no mesmo período. ${ }^{23}$

Voltando ao paisagismo de Mina Klabin, que antecede o primeiro projeto de Roberto Burle Marx para Warchavchik e Lúcio Costa - a casa Schwartz, de 1932 - o fato é que havia uma referência à flora nativa que se coadunava perfeitamente, por contraste, aos volumes puros sob o céu tropical.

A imprensa da época não deixou de notar este aspecto já na primeira casa de Warchavchik, a casa da rua Santa Cruz. Em sua edição de 17 de junho de 1928, o Diário Nacional apresentava a obra em meia página de reportagem que terminava observando "a consonância da arquitetura com o jardim, brasileiro pela utilização, corajosa e trabalhada, da flora em seu estado nativo onde os cactos e as palmeiras 'dão ao conjunto uma nota feliz de tropicalismo e disciplina'" ${ }^{24}$

Nos projetos que realiza em São Paulo, principalmente na casa do dr. Walter T., em 1930-1931 (Figura 5), Acosta incorpora cactos, dracenas e palmeiras (residência do professor J.K.) na ambientação externa. Difícil acreditar, depois de assinalar-se a presença do cacto na poesia de Manuel Bandeira, em obras de Lasar Segall e de Tarsila do Amaral, que se trata de mais uma coincidência na trajetória que Acosta compartilha com seu conterrâneo e colega de turma fixado no Brasil. Se repararmos em outro detalhe do projeto, a proteção das aberturas, veremos que elas são bastante semelhantes às utilizadas por Warchavchik na casa da rua Itápolis (Figura 6), em exposição entre 24 de março e 20 de abril de 1930, e com ampla divulgação em imagens pela imprensa da época - basta lembrar que é ao deparar-se com uma dessas fotos em uma revista que Lúcio Costa começará a simpatizar com a arquitetura moderna. Na realidade, contudo, tratava-se provavelmente de uma veneziana padrão, tal como uma similar, confeccionada em madeira e com mecanismo de enrolar, anunciada pela 


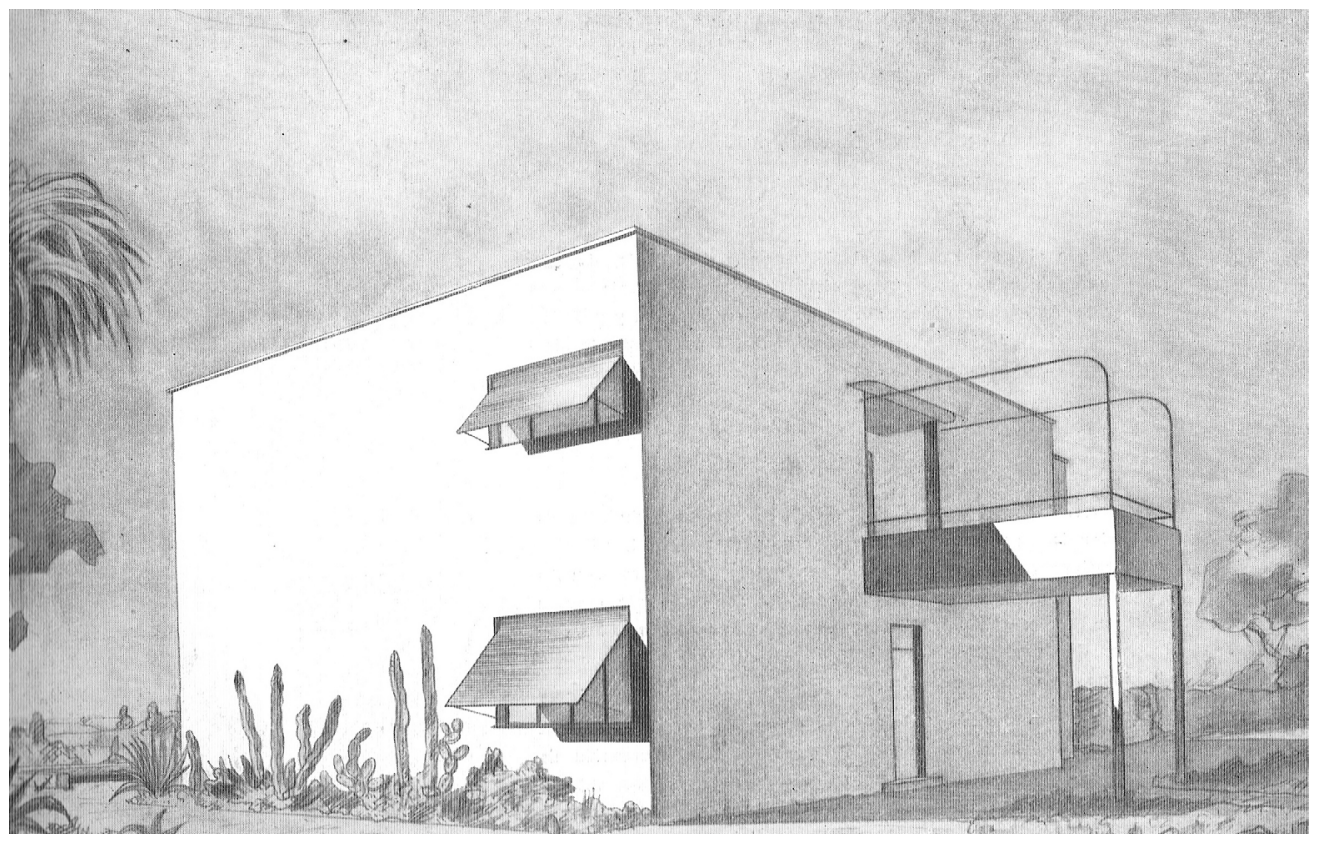

Figura 5 - Projeto da casa do dr. Walter T. por Wladimiro Acosta, 1930. Fonte: Acosta (1936, p. 30).

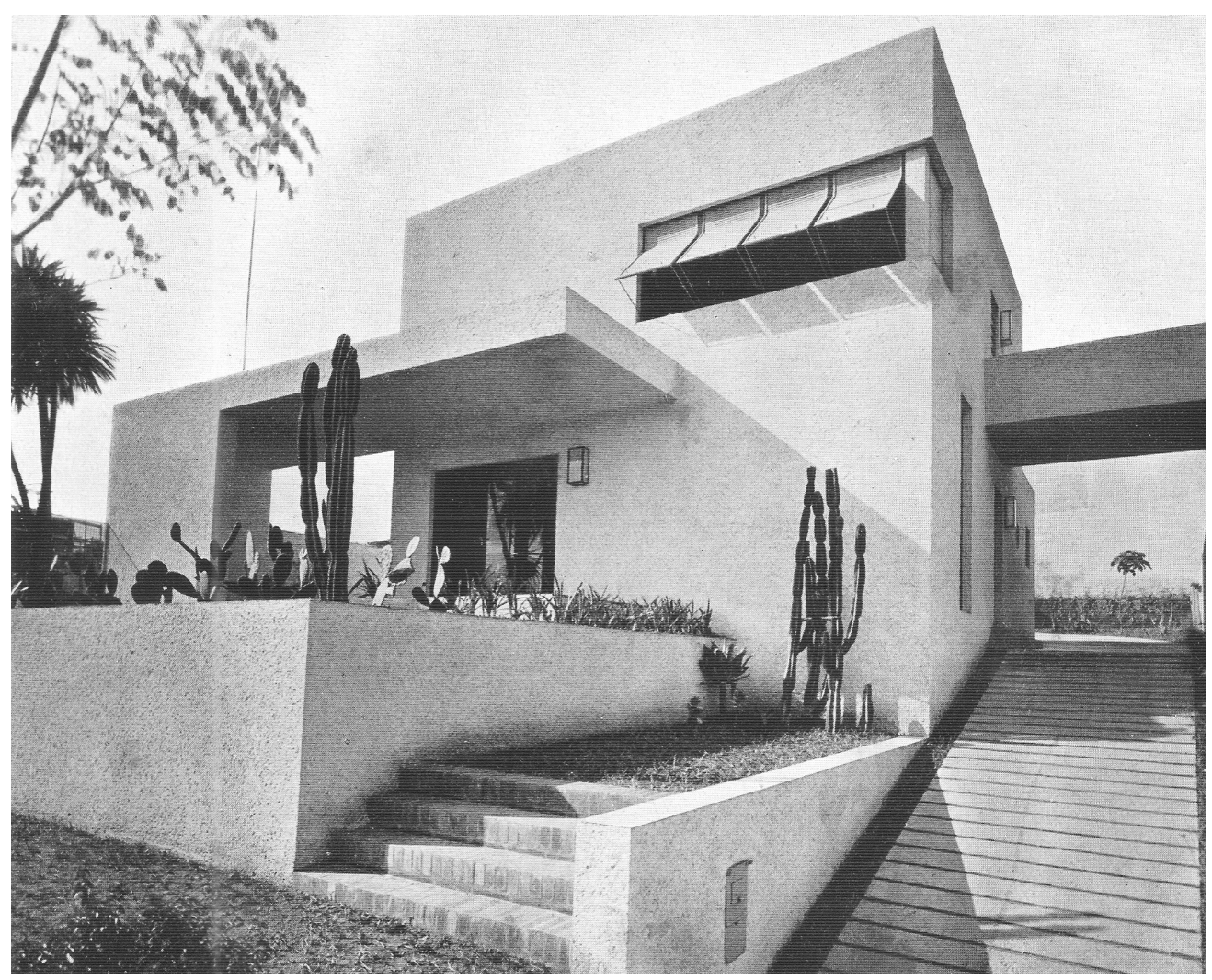

Figura 6 - Casa modernista projetada por Gregori Warchavchik. Fonte: Sartoris (1932). 
26. Liernur (2007, p. 291).

27. Ver a noção de "nacional estrangeiro" em Miceli (2003).

28. Para além das cortinas que aparecem no projeto para uma casa no subúrbio de Buenos Aires, em 1928.

29. Frampton (2001, p. 10).

30. Lira (2011, p. 43).

31. Gordon Cullen chega mesmo a publicar, em $A$ paisagem urbana, imagens de obras de Warchavchik (p. 176) e Oscar Niemeyer (p. 170-172), chamando atenção para o tema.

32. Andrade (2000). firma Pagani \& Castier nas páginas da Revista de Arquitetura, ${ }^{25}$ do diretório da Escola Nacional de Belas-Artes, em meados dos anos 1930.

Detalhes pequenos, mas não tanto. Liernur propõe que Acosta "no podia buscar raíces, y como hubiera resultado incomprensible proponer una armonía" de sua arquitetura com a "Tierra", dada a "alucinante chatura del río y la llanura en medio de la desolación horizontal de Buenos Aires", ele a imagina com "el cielo y el aire". ${ }^{26}$ No caso dos projetos brasileiros, tal observação não se aplica cabalmente, pois é feita, nitidamente, uma concessão à terra, à paisagem - um recurso quase "pictórico" não isento de contradições, por certo. ${ }^{27}$ Tomando-se em conta os projetos que Acosta desenvolve em sua passagem pela Alemanha em meados dos anos 1920, pode-se aventar que inicia por esse momento ${ }^{28}$ sua preocupação com a proteção solar, tão característica das propostas de Vivienda y ciudad que culminam no sistema Helios.

A referência à "bela, áspera, intratável" flora nativa, em contraste com os volumes de pureza geométrica, é algo significativo para alguém que havia se inclinado em direção ao caminho art nouveau de Fomin, ao mesmo tempo em que tomava conhecimento da obra corbusiana em fase figurativa similar. $\bigcirc$ antigo mestre de Le Corbusier, Charles l'Eplattenier, "na maneira Jugendstil da época", havia proposto "criar uma nova cultura da região do Jura amplamente baseada em sua flora e fauna". ${ }^{29}$ Mesmo nos tempos de Odessa, é possível encontrar, no debate arquitetônico de então, ecos semelhantes de pesquisa "de matriz secessionista, de valores representativos da cultura russa". ${ }^{30}$ Tendo simplificado a ornamentação, nas propostas romanas de 1921, bem mais do que Warchavchik e, provavelmente, tomando contato com a obra deste nos primeiros anos da década seguinte, a incorporação da referência à paisagem, em contraste com o rigor da arquitetura, ${ }^{31}$ pode parecer um expediente banal atualmente. No entanto, constituía uma solução, em muitos sentidos, mais sofisticada do que utilizar a fauna e a flora como temas na ornamentação arquitetônica. Justapostos, os duplos contrastes - orgânico/geométrico, vegetal/mineral, áspero/liso, intratável/funcional, primitivo/civilizado - elevavam a beleza da flora local, tornando-a sofisticada, ao mesmo tempo em que naturalizavam a arquitetura maquinista, que parecia, assim, brotar espontaneamente entre a vegetação como se fosse um acontecimento evolutivo natural da cultura brasileira. Dialeticamente, porém, assim como o cacto de Bandeira fundia a visão ao mesmo tempo profunda e prosaica do poeta, a realidade física e social do Brasil, a herança artística europeia e o mito, tais contrastes falam das possibilidades e desacertos "de um país ainda por fazer e já por consertar". ${ }^{32}$ 
Como assinala Liernur, a construção de aparatos arquitetônicos especialmente pensados como instrumentos de "controlada exposición de los cuerpos al aire y al sol cuenta, a principios de los treinta, con un amplio campo de experimentaciones en el debate internacional, especialmente en torno a la arquitectura hospitalaria, el 'sanatorium'". ${ }^{33}$ Neste registro, Liernur aponta o terrassen typ e a origem genética comum das separações entre leitos de hospital e as cortinas que isolavam homens e mulheres do Norte dos olhares curiosos, durante seus banhos de sol, em casas como as de Hans Scharoun em Weissenhof - em relação à qual a residência do Dr. Walter T. de Acosta (Figura 5) possuía uma semelhante armação para cortinas na fachada principal. Sobre o terrassen typ havia aparecido, em 1929, uma publicação de Richard Döcker, com obras, além do próprio Döcker, de Marcel Brever, Adolf Loos, Peter Behrens, Byvoet, Le Corbusier, André Lurçat, Robert Mallet-Stevens, Richard Neutra, J. J. P. Oud, Bruno Taut, Otto Wagner. ${ }^{34}$ Nela constavam, em termos de programa, hospitais, prédios comerciais, residências, siedlungs. Entretanto, como se mostrou, os terraços já estavam presentes na proposta para Tien-Tsin de Acosta (Figura 3) e, em sendo assim, provavelmente incorporavam outra(s) referência(s).

Antes de identificar as experimentações internacionais citadas acima com a necessidade de sol de um genérico "homem do Norte", como uma espécie de condição ontológica, é importante não esquecer que variantes desta "arquitetura solar" também tinham adeptos no Sul... dos Estados Unidos e da Europa. No primeiro caso havia as experiências californianas de Rudolf Schindler e Richard Neutra em seus projetos residenciais para o doutor Philip Lovell - a casa de praia em Newport Beach (1925-1926) de Schindler e a Lovell Health House em Los Angeles (1927) concebida por Neutra. No segundo, é possível ver, em uma proposta de Adalberto Libera para Trípoli, publicada desde a primeira edição (1932) de Gli elementi dell'a architettura funzionale, de Alberto Sartoris, ${ }^{35}$ espaços cobertos distintos, com lajes, pérgolas e pequenas abóbadas, alternando-se e criando situações de exposição variadas, para personagens com uma banhista deitada ao sol. Acima, à direita, o norte é associado às palavras "sombra e mar", e o sul, ao "sol" e ao ghibli - tudo indica uma referência ao quibli, o cálido vento do deserto. $\bigcirc$ elementarismo na conformação dos espaços - piso/parede/teto/ vazio - traduz-se em uma arquitetura cujo programa único parece ser o banho de sol. Similar, nesse sentido, é o caso de algumas obras do revival neopompeiano, em busca de uma condição mediterrânea, como a Villa Latina, apresentada na Trienal de 1930 por Pietro Bottoni, que clamava por um "spirito dele construzioni 
36. Poderia ser esta, genericamente falando, a referência de Acosta para os terraços das propostas romanas dos anos 1920 ?

37. Bottoni apud Cresti (19--, p. 104).

38. Carranza; Lara (2014).

39. Liernur (2007, p. 284). latine, l'equilibrio delle masse, dall'uso di vitta all'aperto di quei popoli mediterranei, le logge, gli atri e le terraze, ${ }^{36}$ dalle case dele riviere del Tirreno, il suo colore". ${ }^{37}$

Com elementos de proteção solar bastante tímidos, a casa latina de Bottoni, qual camaleão, procura integrar-se na paisagem de cores quentes, entre o mar, palmeiras e elevações com perfis assemelhados a vulcões, em contraste, portanto, com a série complexa de "tabiques, telas, muros, cristales y placas móviles" que transformam interiores em exteriores e vice-versa nas residências de Acosta. $O$ arquiteto argentino propõe não só a integração da arquitetura aos exteriores como a "captura" da ambiência externa para a domesticidade dos interiores, criando um conjunto de situações ricas e cambiantes.

Para Luis Carranza e Fernando Lara, o sistema de proteção solar (Helios) e a variabilidade ambiental proposta por Acosta, que inclui ainda espaços sem função definida, dedicados ao "movimento" - ginástica, dança etc. -, destacam de maneira "teatral" tanto as próprias residências, enquadrando-as em uma moldura arquitetônica (os elementos do sistema Helios), quanto, e talvez principalmente, as atividades nelas desenvolvidas, como se fossem acontecimentos ou fenômenos para os quais a arquitetura doméstica seria uma espécie de palco. ${ }^{38}$ Toldos e outros dispositivos retráteis, inclusive, aproximam-se da maquinaria teatral - bambolinas, urdidura etc. - em sua capacidade de multiplicação de situações espaciais para a ambientação das cenas. E não deixa de ser significativo, apesar da observação de Liernur de que "el sistema Helios no tuvo continuación alguna, ni siquiera entre los discípulos o seguidores de Acosta", ${ }^{39}$ que um ou outro profissional argentino tenha se deixado seduzir por algumas de suas possibilidades, como a adoção do terrassen typ associado ao uso de toldos retráteis.

Em uma publicação intitulada Arquitectura Moderna Año 1940, publicada em Buenos Aires em 1939, pelo mesmo editor de Vivienda y ciudad, Ignacio Aresti, aparecem projetos de dois profissionais. Deixando para outra oportunidade uma análise do volume como um todo, interessa no momento assinalar a presença de toldos retráteis em terraços de alguns dos desenhos apresentados por Carlos J. Perrone (Figura 7). Sempre e novamente detalhes reveladores: a expressão gráfica de Perrone lembra, em parte, a de Acosta em Vivienda y ciudad (figura 8) - que, como é possível notar em um exame dos desenhos apresentados no volume, incorpora em outras ocasiões alguma coisa dos croquis de Le Corbusier. Antes de um aspecto secundário, na medida em que Acosta trabalhou com produções teatrais, talvez fosse consequente averiguar até que ponto a opção por um ou outro tipo de expressão gráfica fornece indícios daquilo que o arquiteto procurava demonstrar com um desenho.

Como contraponto à eventual observação de que Perrone não faz referências tão diretas à linguagem compositiva de Acosta e de que o sistema 


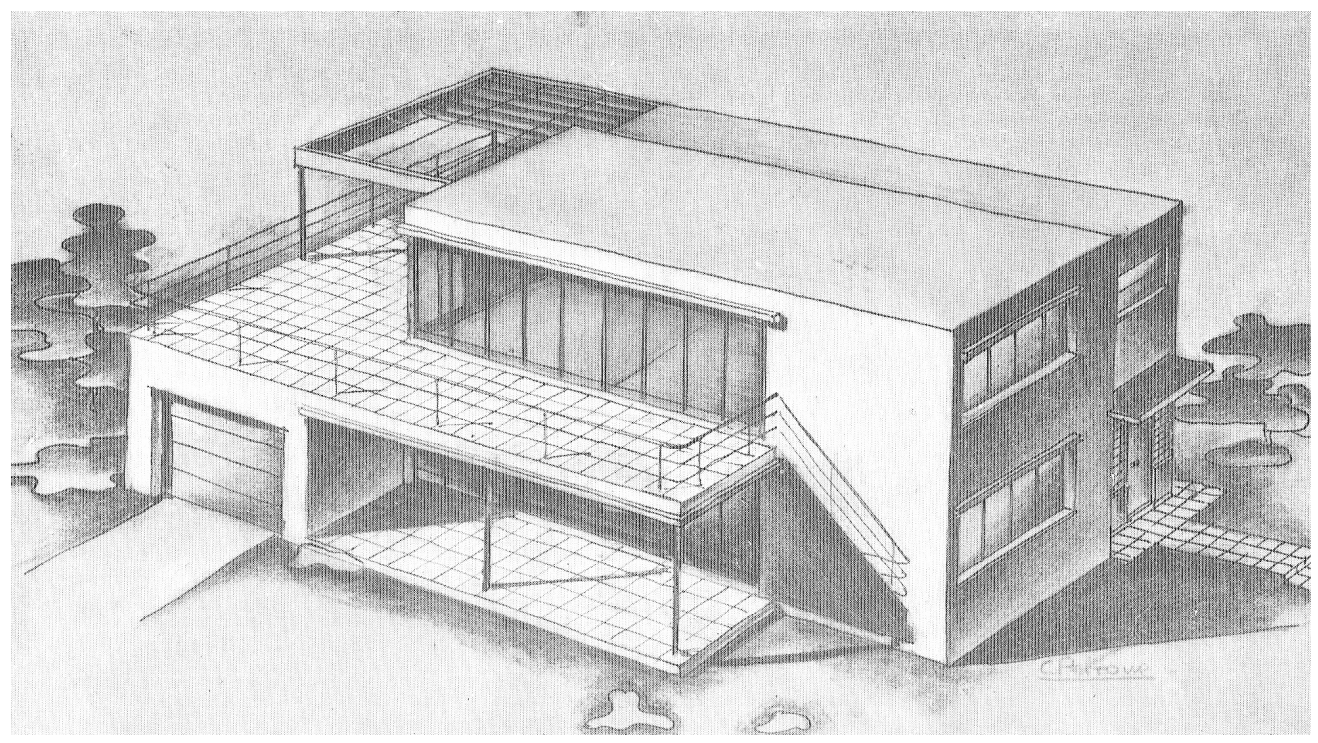

Figura 7 - Projeto de residência por Carlos J. Perrone. Fonte: Arquitectura Moderna Año 1940 (1939).

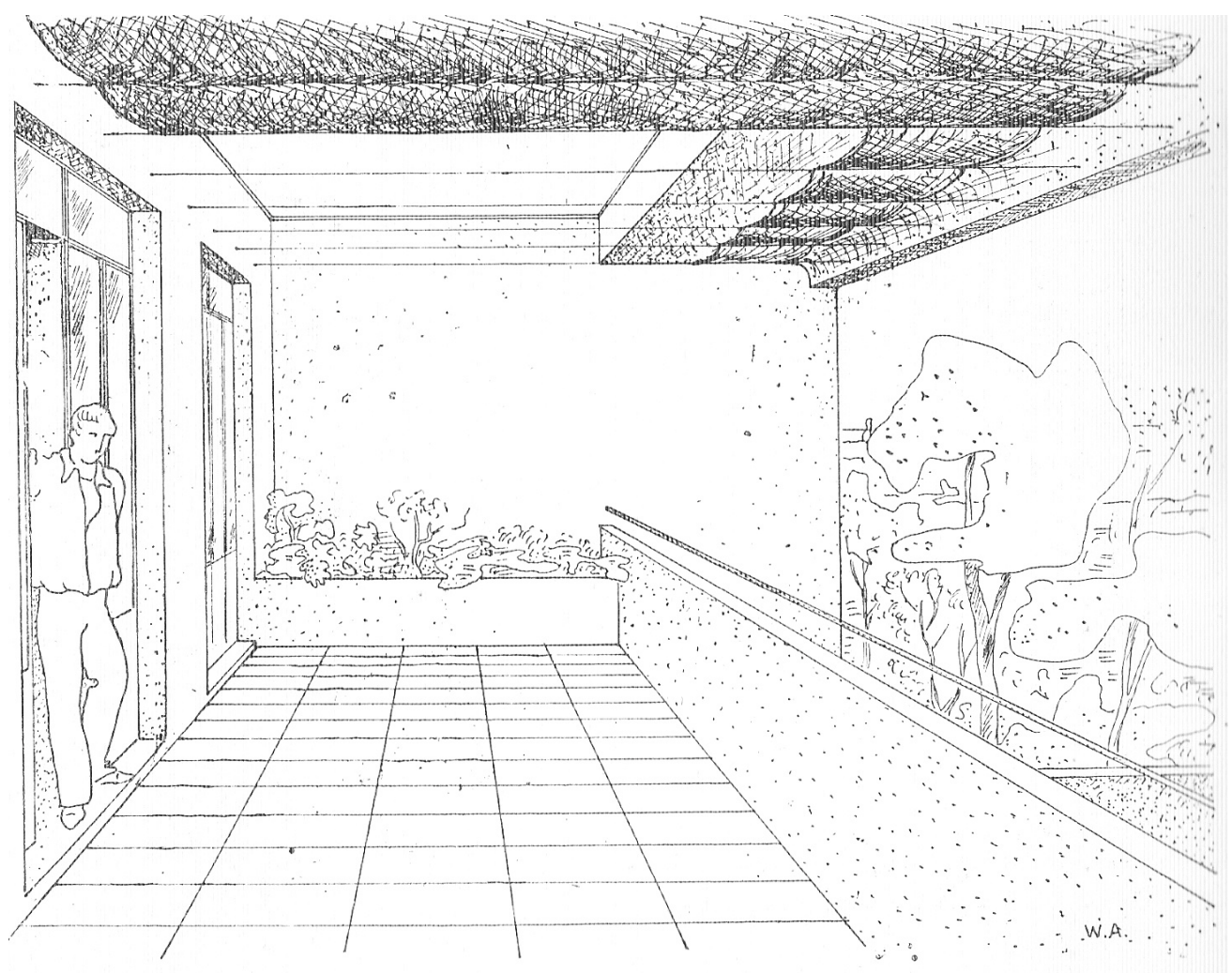

Figura 8 - Projeto de residência nos arredores de Buenos Aires por Wladimiro Acosta, 1933-1934. Fonte: Acosta (1936, p. 44). 
40. Álbum de Proyectos de Arquitectura (19--, p. 32). retrátil que usa nos toldos não é o mesmo proposto por este último, deve-se fazer notar que, desde a primeira edição, em Vivienda y ciudad, Acosta reserva os direitos autorais do material que apresenta. A assimilação de Perrone de algumas das propostas de Acosta, em um "álbum de projetos" - uma literatura "menor" como Arquitectura Moderna Año 1940, poderia passar por algo com caráter anedótico. Tal opinião, não obstante, deve ser temperada com a observação de que outros profissionais também parecem ter se interessado pelas possibilidades oferecidas pela utilização de terraços e coberturas retráteis; com a matização entre luz, sombra e penumbra; e a gradação cambiante da integração interior-exterior.

É o caso de Onofre Pacenza, então professor de desenho da Academia Nacional de Belas-Artes da Argentina e pintor com reconhecimento crescente ao longo dos anos seguintes. Seu interesse pelos bairros da periferia e da ribeira boquense, onde capta a atmosfera local e os hábitos dos moradores, parece de alguma forma transparecer em suas perspectivas. Estas assumem um caráter algo teatral, em uma aproximação à poética gráfica de Acosta: os terraços em seus projetos residenciais povoam-se de pequenos grupos, pessoas sentadas à volta de uma mesa, casais conversando enquanto tomam café, mulheres reunidas ao redor de suas xícaras de chá (Figura 9). Na apresentação de outro de seus projetos é descrita "una terraza cubierta para una merienda familiar comunicada con la cocina por medio de un montaplatos". 40

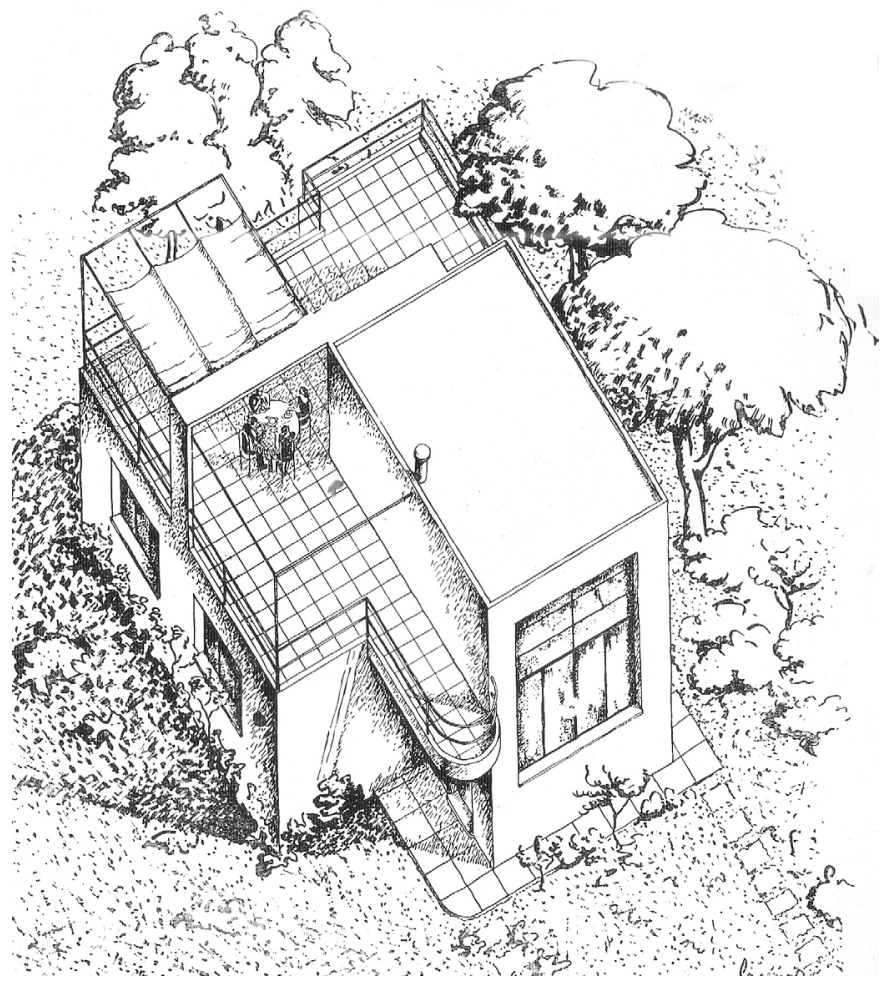

Figura 9 - Projeto de residência por Onofre Pacenza. Fonte: Álbum de Proyectos de Arquitectura (19-, p. 46). 
Mais do que falar de "influência" parece significativo observar os processos

de circulação de ideias entre estratos diferenciados da cultura arquitetônica, seja nos planos geográficos Norte-Sul, Sul-Sul etc., seja entre camadas culturais propriamente ditas. Vivienda y ciudad é, certamente, uma das publicações mais importantes da vanguarda sul-americana no período. Desde sua primeira edição, como dito, Acosta reserva os direitos autorais do material que apresenta, alertando para o fato de que a "obra no es un catálogo de proyectos a copiar [...] sus proyectos no pueden ser parcial o totalmente realizados" sem a concordância do autor. Este não parece ser o caso de Arquitectura Moderna Año 1940 ou do Álbum de Proyectos de Arquitectura (Figura 9). Como indica o segundo título, tratam-se de "álbuns de projetos", justamente, catálogos de projetos para copiar, dirigidos, em grande parte, para um público leigo, podendo ser entendidos como instrumentos diluidores ou de popularização das ideias das vanguardas, a partir de assimilações parciais e recriações. De fato, na apresentação de Arquitectura Moderna Año 1940 lê-se:

entre nosotros, advertimos que, en cierto sentido, es escasa la educación al respecto, deficientes los conocimientos populares acerca de las condiciones primordiales exigibles a la vivienda, en relación con su función, sobre todo en las zonas alejadas de los grandes centros de población.

Comprobada esta situación local, ha sido nuestro propósito propender a su mejoramiento: difundir conocimientos básicos sobre el tema. ${ }^{41}$

É bom não esquecer que o editor de Vivienda y ciudad, Ignacio Aresti, era o mesmo de Arquitectura Moderna Año 1940.

Nesse sentido, dos processos de circulação de ideias entre estratos da cultura arquitetônica, o exemplar em minha biblioteca da primeira edição de Vivienda y ciudad traz uma discreta anotação junto ao projeto para o "periodista R. de P. (São Paulo, 1931 1)", logo após a observação de Acosta de que a "frente oeste" era uma péssima orientação: um sinal de interrogação. Como o volume foi adquirido no Brasil, a interrogação poderia indicar o interesse de um profissional atuando no mercado brasileiro em relação ao correto enfrentamento do problema da insolação?

Já o de Arquitectura Moderna Año 1940, pertencia a Affonso Moreira da Silva, aluno da Escola Nacional de Belas-Artes, onde se formaram Lúcio Costa, Oscar Niemeyer e Affonso Eduardo Reidy, entre outros, transformada, em 1945, na Faculdade Nacional de Arquitetura da Universidade do Brasil - indício, mesmo mínimo, da circulação de referências entre a Argentina e o Brasil no início dos anos 1940, antecedendo, por exemplo, a publicação, na versão em espanhol 
43. Warchavchik já havia aparecido em uma edição da revista Nuestra Arquitectura de dezembro de 1932.

44. Stinco (2010, p. 99).

45. Rocha (2009). Revisto e ampliado em Rocha (2014).
(Arquitectura de Hoy), do número da revista francesa L'Architecture d'Aujourd'hui42 de setembro/outubro de 1947, dedicado à arquitetura moderna brasileira, ${ }^{43} \mathrm{e}$ que, certamente, possuía leitores no país vizinho.

Segundo a pesquisadora Claudia Stinco, o exemplar da segunda edição de Vivienda y ciudad pertencente à biblioteca da Faculdade de Arquitetura e Urbanismo da Universidade de São Paulo foi doado pelo próprio Wladimiro Acosta, sendo datado e firmado em 1957.44 No mesmo ano, o escritório SEPRA (Santiago Sánchez Elía, Federico Peralta Ramos e Alfredo Agostini) realizou um projeto para a residência Mattarazzo, em São Paulo. Dois anos depois, foi publicado em Buenos Aires, pelo Instituto de Arte Americano e Investigaciones Estéticas, a primeira monografia sobre a obra de Lúcio Costa. ${ }^{45}$

Some-se a estes fatos a contribuição, ainda a ser corretamente dimensionada, de profissionais argentinos ao campo da arquitetura e urbanismo brasileiro e viceversa, e as peças do mosaico estão aí... Se elas constituem detalhes pequenos demais para serem aproveitados ou spie para a montagem de um painel mais amplo, é uma questão que reside, em grande medida - ou, pelo menos, na medida certa - em como mirarlas. 


\section{REFERÊNCIAS}

ACOSTA, Wladimiro. Vivienda y ciudad. Buenos Aires: Ignacio Aresti, 1936.

ÁlBUM DE PROYECTOS DE ARQUITECTURA MODERNA. Buenos Aires, [19--]. 2. ed.

ANDRADE, Fábio de Souza. Apresentação. In: ARRIGUCCI JR., David. O cacto e as ruínas. São Paulo: Duas Cidades; Editora 34, 2000.

ARCHITECTURAL FORUM. Boston, 1928-1929.

ARQUITECTURA MODERNA AÑO 1940. Buenos Aires: Ignacio Aresti, 1939.

ARRIGUCCI JR., David. O cacto e as ruínas. São Paulo: Duas Cidades; Editora 34, 2000.

BRUMFIELD, William. The origins of modernism in Russian architecture. Berkeley: University of California Press, 1991.

CARRANZA, Luis E.; LARA, Fernando Luiz. Modern architecture in Latin America: art, technology, and utopia. Austin: University of Texas Press, 2014.

CRESTI, Carlo. Architettura e fascismo. Firenze: Vallecchi, [19--].

CULLEN, Gordon. Paisagem urbana. Lisboa: Edições 70, 2017.

DÖCKER, Richard. Terrassen typ. Stuttgart: [s.n.], 1929.

FALBEL, Anat. Sobre utopia e exílios na América Latina. Politeia, Vitória da Conquista, v. 9. n. 1, p. 107-140, 2009.

FERRAZ, Geraldo. Warchavchik e a introdução da nova arquitetura no Brasil: 1925 a 1940. São Paulo: Masp, 1965.

FRAMPTON, Kenneth. Le Corbusier. London: Thames \& Hudson, 2001.

GINZBURG, Carlo. Entrevista. In: PALLARES-BURKE, Maria Lúcia. As muitas faces da história: nove entrevistas. São Paulo: Editora Unesp, 2000. p. 269-306.

L'ARCHITECTURE D'AUJOURD'HUI. Paris, n. 13, set. 1947.

LE CORBUSIER. Vers une architecture. Paris: Crès, 1923. 
LIERNUR, Jorge Francisco. Wladimiro Acosta y el expresionismo alemán: consideraciones acerca de los fundamentos ideológicos del sistema Helios. In: GAITE, Arnaldo. Wladimiro Acosta. Buenos Aires: Nobuko, 2007. p. 261-304.

LIRA, José Tavares. Warchavchik: fraturas da vanguarda. São Paulo: Cosac Naify, 2011.

MICELI, Sergio. Nacional estrangeiro: história social e cultural do modernismo artístico em São Paulo. São Paulo: Companhia das Letras, 2003.

ONS, Patricia: CAMPOS, Cecilia. Reflexiones sobre la evolución en la planta de la vivienda unifamiliar. In: GAITE, Arnaldo. Wladimiro Acosta. Buenos Aires: Nobuko, 2007. p. 367-371.

RECA, Telma. Del libro Wladimiro Acosta: Vivienda y Clima. In: GAITE, Arnaldo. Wladimiro Acosta. Buenos Aires: Nobuko, 2007.

REVISTA DE ARQUITETURA. Rio de Janeiro, n. 6, 1934.

ROCHA, Ricardo. Lúcio Costa e a Argentina: da boa tradição ao ser americano. Arquitextos, São Paulo, ano 8, n. 096.02, dez. 2009.

. Tránsitos americanos: Lúcio Costa y la Argentina. In: ALANIS, Enrique X. de Anda; PADILLA, Alejandra Contreras (Org.). Tránsitos en el circuito América Latina, Europa y Estados Unidos en el periodo de la pós-guerra (1945-1960): redefiniciones en la arquitectura y el urbanismo. México, DF: UNAM, 2014. p. 73-83.

SARTORIS, Alberto. Gli elementi dell'a architettura funzionale. Milano: Ulrico Hoelpi, 1932.

STINCO, Claudia. Quatro interpretações da casa moderna na América Latina. 2010. 343 f. Tese (Doutorado) - Faculdade de Arquitetura e Urbanismo, Universidade Mackenzie, São Paulo, 2010.

WARCHAVCHIK, Gregori. Algunas obras del arquitecto. Nuestra Arquitectura, Buenos Aires, dez. 1932.

YEZHEGODNIK OBSHCHESTVA ARKHITEKTOROV-KHUDOZHNIKOV. [S.1.], n. 1, 1906.

\section{(cc) BY}

Artigo apresentado em 09/03/2017. Aprovado em 01/08/2017

All the contents of this journal, except where otherwise noted, is licensed under a Creative Commons Attribution License 